\title{
Gastric Adenoma, Gastric-Type
}

National Cancer Institute

\section{Source}

National Cancer Institute. Gastric Adenoma, Gastric-Type. NCI Thesaurus. Code $C 95775$.

A neoplastic polyp that arises from the stomach. It is characterized by the presence of gastric epithelial differentiation. It includes pyloric gland adenomas and foveolar-type adenomas. 